\title{
MODELING THE COMPRESSIBILITY BEHAVIOR OF HARD RED WHEAT VARIETIES
}

\author{
A. P. Turner, M. D. Montross, S. G. McNeill, M. P. Sama, M. E. Casada, \\ J. M. Boac, R. Bhadra, R. G. Maghirang, S. A. Thompson
}

\begin{abstract}
The bulk density of grain in a storage structure varies vertically and horizontally due to the overburden pressure created by the cumulative weight of the overlying material. As the overburden pressure increases, the stored material compacts. This compaction is believed to be caused by rearrangement of kernels along with higher intergranular stress between particles, leading to kernel deformation. This compaction is of primary concern when estimating the amount of grain in a storage structure. In this comprehensive study, confined uniaxial compression tests were conducted on 27 different samples of hard red winter wheat, at three moisture levels, over the range of pressures typically encountered in storage structures (0 to $138 \mathrm{kPa}$ ). Mathematical models using the prior, modified, and new forms of the bulk density equation were evaluated to describe the resulting pressure-density relationship as a function of moisture content. With the new data set, the modified version of the Page equation had the lowest root mean square error (RMSE) of $4.7 \mathrm{~kg} \mathrm{~m}^{-3}$, while the other equations, including the original polynomial equation used in the WPACKING program, had RMSEs between 6.0 and $7.1 \mathrm{~kg} \mathrm{~m}^{-3}$. The models were validated using previously published compressibility data and the root mean square prediction error was determined to vary from 8.1 to $13.4 \mathrm{~kg} \mathrm{~m}^{-3}$. Four of the best performing models were subsequently applied to field measurements from 35 concrete and 16 steel bins. When applied to the field data a slight bias was observed in steel and concrete bins, but several of the models, including the modified Page and polynomial models, produced an average error of less than $2 \%$ from the measured grain mass.
\end{abstract}

Keywords. Bulk density, Bulk properties, Compressibility, Grain storage, Packing, Test weight.

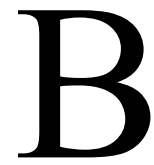

ulk density is an important parameter commonly used to estimate the mass of grain in a storage structure. Numerous studies involving both grains and powders have shown that the pressure caused by the cumulative weight of the overbearing material in a storage structure causes the stored material to compress, which results in an increase in bulk density. This increase in bulk density caused by the overburden pressure is commonly referred to as packing or compaction and is of

Submitted for review in July 2015 as manuscript number PRS 11432; approved for publication by the Processing Systems Community of ASABE in March 2016.

Mention of trade names or commercial products in this article is solely for the purpose of providing specific information and does not imply recommendation or endorsement by the USDA. The USDA is an equal opportunity provider and employer.

The authors are Aaron P. Turner, Engineer Associate, Michael D. Montross, ASABE Member, Professor, Samuel G. McNeill, ASABE Member, Associate Extension Professor, and Michael P. Sama, ASABE Member, Assistant Professor, Department of Biosystems and Agricultural Engineering, University of Kentucky, Lexington, Kentucky; Mark E. Casada, ASABE Member, Research Agricultural Engineer, USDA-ARS Stored Product Insect and Engineering Research Unit, Manhattan, Kansas; Josephine M. Boac, ASABE Member, Research Associate, Rumela Bhadra, ASABE Member, Research Associate, and Ronaldo G. Maghirang, ASABE Member, Professor, Department of Biological and Agricultural Engineering, Kansas State University, Manhattan, Kansas; Sidney A. Thompson, ASABE Member, Professor, College of Engineering, University of Georgia, Athens, Georgia. Corresponding author: Michael Montross, 128 Barnhart Bldg., University of Kentucky, Lexington, KY 40546-0276; phone: 859-218-4319; e-mail: michael. montross@uky.edu. primary concern when estimating the amount of grain in storage from volume measurements.

At low overburden pressures, the majority of the density increase is believed to be caused by particle rearrangement and reduction in void space (Thompson and Ross, 1983). At high overburden pressures, it is believed that intergranular particle forces play a larger role in resisting compaction, and eventually the kernels themselves are compressed (Thompson et al., 1987). As the overburden pressure increases, compaction occurs at a decreasing rate asymptotically. The focus of these studies has been on free-flowing, granular materials (i.e., corn, soybeans, and wheat).

Bulk density and packing within grain storage structures is influenced by numerous factors, including grain type, variation in kernel size, moisture content, test weight, growing season, and most importantly the overburden pressure experienced during storage (Thompson and Ross, 1983). Research associated with grain compressibility has shown that the bulk density of compressed grain samples (corresponding to local bulk density in deep storage bins) is primarily a function of grain type, initial test weight, overburden pressure, and grain moisture content when there are low amounts of dockage and foreign material (Thompson et al., 1987). Other factors, including vibration, have also been shown to influence grain compaction (Hao et al., 1994). Several approaches have been developed to account for this non-uniform density when measuring grain inventory. These include correction factors based on bin size, grain type, and test weight that are used by regulating bod- 
ies (USDA, 2011, n.d.) to account for packing in bins.

Janssen's equation (Janssen, 1895) has been used for over 100 years to predict pressures within grain storage structures (Ross et al., 1979). To solve Janssen's equation, a number of parameters are needed, including the lateral-tovertical pressure ratio $(k)$, the coefficient of friction of grain on the bin wall $(\mu)$, and the bulk density of the granular material $(D)$. In work done on shelled corn (Ross et al., 1979), the vertical pressures in a grain bin were estimated using the differential form of Janssen's equation in which the material properties of grain varied with moisture content and pressure. Thompson et al. (1987) assumed that the differential form of Janssen's equation could be used not only to predict the pressures within a bin but also as an inventorying tool to predict the compressibility and packing of the stored material. In inventorying grain, it is typically assumed that $k$ and $\mu$ are constant throughout the bin, and the bulk density varies with depth caused by changes in overburden pressure. In order to solve Janssen's equation numerically and estimate the total mass of grain in a structure, the bulk density must be solved as a function of depth (overburden pressure). Toward that end, equations for each type of stored material can be developed to describe the changes in bulk density with respect to grain type, initial test weight, overburden pressure, and grain moisture content. The WPACKING program (Thompson et al., 1987, 1991) was developed to predict the mass of grain in a storage structure based on this principle.

Bhadra et al. (2015) and Boac et al. (2015) performed additional validation of the WPACKING program in commercial and farm bins for corn and hard red winter wheat (HRWW). These studies also compared WPACKING to estimates made using two other common inventorying methods used by the USDA Farm Service Agency (FSA) and USDA Risk Management Agency (RMA). Both of these methods use empirically developed adjustment factors based on test weight and bin diameter to account for packing and adjust to standard bushels. Both studies found that errors were on the order of $-1.3 \%$ to $3.8 \%$ when packing was determined using WPACKING, although errors might be further reduced with refinements in the pressure density relationship used in WPACKING.

Numerous confined uniaxial compression studies have been performed on grain and feed ingredients. Various models have been proposed to describe changes in bulk density as a function of overburden pressure and moisture content with various types of grain. Some of the original work was performed by Clower et al. (1973), and the procedure was further refined by Thompson and Ross (1983). Thompson and Ross (1983) used a steel box with a chamber $30 \mathrm{~cm} \times 30 \mathrm{~cm}$ square and $10 \mathrm{~cm}$ in height that contained grain during testing. A removable steel plate was used to seal the test chamber. The base of the chamber contained a flexible rubber diaphragm that allowed compressed air to be applied underneath the diaphragm, which in turn applied vertical pressure uniaxially to the grain. This produced an equivalent overbearing pressure via the compressed air to simulate the conditions found in grain storage bins. The test chamber was filled using a spring-loaded box
(Thompson, 1980) to create a consistent initial loading condition that was similar to the Winchester test cup (USDA, 1999).

Clower et al. (1973) examined the compressibility and lateral-to-vertical pressure ratio ( $k$ value) of soybean meal, corn meal, and wheat that is used in Janssen's equation. Thompson and Ross (1983) tested the compressibility and friction coefficients of wheat on various types of bin surfaces. Thompson et al. (1987) examined the packing of various whole grains. The effect of varying levels of broken corn and foreign materials (BCFM) on the pressure density relationship was studied by McNeill et al. (2004) in corn and by McNeill et al. (2008) in feed ingredients.

\section{OBJECTIVES}

The objective of this study was to evaluate the suitability of various models to quantify the compressibility of a wide range of HRWW samples at three moisture contents, nominally $10 \%, 12.5 \%$, and $14 \%$ w.b., over an overburden pressure range of 0 to $138 \mathrm{kPa}$. The compressibility models developed based on the laboratory data were then validated using previous compressibility data from Thompson et al. (1987) and field measurements of concrete and steel bins presented by Boac et al. (2015).

\section{Materials ANd Methods COMPRESSIBILITY MODELS}

Numerous models for packing of bulk powder and freeflowing grain in storage have been proposed. $\mathrm{Gu}$ et al. (1992) evaluated multiple models to fit the bulk densityconsolidation relationship of various products including sand, sugar, PVC powder, and fine coal. Table 1 shows the candidate models that were considered in this study. The models examined in this study were drawn from differing applications, yet many were similar to models evaluated by Gu et al. (1992).

A moisture-pressure interaction term $(f \cdot M \cdot P$; see Nomenclature for definitions) was included in many of the models to account for the effect of moisture on bulk density. When possible (all models except eq. 6), the models are shown in the form of $\left(\rho_{i}-\rho_{o}\right)$, which represents only the amount of compaction that occurred within the grain caused by the overbearing weight of the grain above. The $\rho_{o}$ term represents the uncompacted bulk density within the compression chamber after filling, and $\rho_{i}$ represents the density at the varying overburden pressure levels.

Equation 1 is the original polynomial equation used by Thompson et al. (1987) to model the pressure-density relationship of various grains. Equation 2 represents a proposed modified fixed-polynomial model and allows the exponent of the second-order term involving overburden pressure to vary. Equation 3 represents a form of the Page model that has been successfully applied to thin-layer drying of grain (ASABE, 2014), where moisture content is assumed to approach an equilibrium value over time. This form of the standard Page model (eq. 3) was modified from the form presented by Overhults et al. (1973) and takes into account what are believed to be the two primary mechanisms caus- 
Table 1. Models for the pressure density relationship.

\begin{tabular}{cc}
\hline Author & Equation \\
\hline Thompson et al. (1987) & $\rho_{i}-\rho_{o}=a \cdot P+b \cdot \sqrt{P}+f \cdot M \cdot P$ \\
\hline Thompson et al. (1987) ${ }^{[\mathrm{a}]}$ & $\rho_{i}-\rho_{o}=a \cdot P+b \cdot P^{c}+f \cdot M \cdot P$ \\
\hline Overhults et al. (1973) ${ }^{[\mathrm{a}]}$ & $\rho_{i}-\rho_{o}=\left(\rho_{\infty}-\rho_{o}\right) \cdot\left(1-e^{\left(-a \cdot P^{b}\right)}+f \cdot M \cdot P\right.$ \\
\hline Morgan et al. (1975) & $\rho_{i}-\rho_{o}=\frac{a \cdot b+c \cdot P^{d}}{b+P^{d}}+f \cdot M \cdot P$ \\
\hline Steffe (1992) ${ }^{[\mathrm{a}]}$ & $\rho_{i}-\rho_{o}=a(P)^{b} \cdot e^{(c \cdot M)}$ \\
\hline Johanson (cited by Gu et al., 1992) & $\rho_{i}=\rho_{o}(1+a \cdot P)^{b}+f \cdot M \cdot P$ \\
\hline Kawakita and Lüdde (1971) & $\frac{\rho_{o}-\rho_{i}}{\rho_{o}}=\frac{a \cdot b \cdot P}{1+b \cdot P}+f \cdot M \cdot P$ \\
\hline [a] Modified from original form. (3)
\end{tabular}

a] Modified from original form.

ing compaction. The initial mechanism for compaction at low pressures is believed to be primarily the reduction in void space and particle rearrangement. This results in a steep density-pressure curve at pressures up to approximately $25 \mathrm{kPa}$ (Thompson et al., 1987), where the majority of compaction occurs. At pressures between 25 and $100 \mathrm{kPa}$, the rate of compaction slows considerably (Thompson et al., 1987). It was hypothesized that the equilibrium density, at pressures above what typically occurs during storage, approaches the kernel density or perhaps the tapped density. The modified Page model used to predict bulk density includes modified forms of the exponent term and the moisture term, and the equilibrium density was taken as the kernel density.

Other models considered were pulled from other fields that had characteristics similar to the compression results observed. These include the Morgan-Mercer-Flodin (MMF) growth model (Morgan et al., 1975), which allows a nonzero intercept and approaches an asymptote at high pressures, as shown in equation 4 . The model shown in equation 5 was based on the viscosity within a shear thickening fluid with a yield stress (Steffe, 1992) that also matched the general form of the density increase with pressure. Equations 6 and 7 have been used previously to model the volume or bulk density-stress relationship in powders.

\section{COMPRESSIBILITY MEASUREMENT Sample Preparation}

Compression tests were performed on 27 samples of HRWW from varying years, states, and varieties. For each sample, two bags $(23 \mathrm{~kg})$ of grain were purchased from seed dealers in Idaho, Montana, South Dakota, Colorado, Oklahoma, North Dakota, Texas, Kansas, Nebraska, Washington, and Oregon. These were primarily from the 2007 through the 2010 crop years. Ten varieties were tested, which represented most varieties grown in the HRWW growing regions in the U.S. Environmental chambers were used to condition the grain to two different moisture contents ( $10 \%$ and $12.5 \%$ w.b.) that would represent conditions during storage of HRWW (Kenkel et al., 1994). To condition the grain, a bag of wheat was placed in a plastic tub and randomly assigned to one of the environmental chambers. The environmental chambers were set at $32^{\circ} \mathrm{C}$ and $45 \% \mathrm{RH}$ and $21^{\circ} \mathrm{C}$ and $90 \% \mathrm{RH}$, which resulted in the desired nominal moisture contents of $10 \%$ and $12.5 \%$ w.b., respectively. The wheat was mixed by hand on a weekly basis while it equilibrated. Equilibrium was reached after approximately five months. Moisture content was determined from a single sample taken from each replication using a recently calibrated moisture analyzer with a readability of $0.1 \%$ moisture and repeatability of $\pm 0.1 \%$ (GAC 2100, DICKEY-john, Auburn, Ill.). The measured wet basis moisture content was converted to dry basis for use in the models. The $10 \%$ and $12.5 \%$ moisture content levels were completely randomized. A third moisture level was added (nominally $14 \%$ w.b. at a temperature of $35^{\circ} \mathrm{C}$ and $68 \%$ $\mathrm{RH})$ to allow for determination of the regression coefficients for equations 3 and 5 . The samples for the $14 \%$ moisture content level were randomized within that moisture level.

\section{Instrumentation}

The compression chamber originally developed by Thompson and Ross (1983) was used as the basis for the experimental testing. Two chambers identical to those shown by Thompson and Ross (1983), measuring $30 \mathrm{~cm} \times$ $30 \mathrm{~cm} \times 10 \mathrm{~cm}$, were built, and a computer data acquisition system was developed to adjust the pressure and measure the displacement within each chamber. This replaced the manual pressure adjustment and data recording employed in earlier works. The system used by Thompson and Ross (1983) and this system were nearly identical, except the dial indicator was replaced with a linear variable differential transducer (LVDT) and the manual pressure regulator was replaced with the computer-controlled pressure regulator. The displacement recorded with the LVDT had a range of $\pm 15 \mathrm{~mm}$ and a linearity of $<0.2 \%$ full scale output (LD620-15, Omega Engineering, Stamford, Conn.). The pressure was controlled with a voltage to pressure regulator that allowed pressures between 0 and $138 \mathrm{kPa}(0$ and 20 psi) (IP411-020, Omega Engineering). The pressure was recorded using pressure transducers with a range of 0 to 
$207 \mathrm{kPa}$ and an accuracy of $0.25 \%$ (PX-209-030A5V, Omega Engineering). A control program was written in Microsoft Visual Studio to adjust the pressure, monitor the pressure with the transducer during testing, and record the displacement. Operation of the LVDTs was verified using gauge blocks, and the pressure regulator and transducer were calibrated using a water and mercury manometer on a weekly basis.

The pressures evaluated were $0,7,21,34,48,69,103$, and $138 \mathrm{kPa}(0,1,3,5,7,10,15$, and $20 \mathrm{psi})$, which were similar to those used by Thompson et al. (1987). These pressures are typical of the range of pressures found in most on-farm and commercial grain storage structures. A typical concrete silo, $9 \mathrm{~m}$ in diameter and $30 \mathrm{~m}$ tall, has a maximum static vertical pressure of $80 \mathrm{kPa}$, and a large corrugated steel bin, $30 \mathrm{~m}$ in diameter and $30 \mathrm{~m}$ tall, has a maximum static vertical pressure slightly above the range examined at $160 \mathrm{kPa}$ (ASABE, 2011). The pressure and displacement were monitored every second during testing, and the samples were subjected to a 5 min hold time at each pressure level before the displacement and pressure were recorded. Preliminary testing showed this was sufficiently long for the displacement to stabilize. The pressure was then increased linearly to the next level over a $30 \mathrm{~s}$ interval. Due to the non-uniform pressure step size, the loading rate was not constant over the range of pressures. However, the method used by Thompson et al. (1987) was not a constant loading rate either, since the pressure was manually adjusted.

\section{Sample Testing}

Each sample was tested at three moisture levels with four replications. Prior to testing, samples were randomly removed from the environmental chamber and mixed by hand. The sample was assigned randomly to chamber 1 or chamber 2 for testing. Before filling the compression chamber, a vacuum was applied to pull the rubber diaphragm tight against the bottom of the chamber. A filling apparatus was then used to fill the compression chamber. Thompson and Ross (1983) showed that this filling apparatus produced an initial density in the chamber that closely matched the test weight determined using the Winchester bushel test (USDA, 1999). Details of the loading box are given by Thompson (1980). The grain was then leveled with the top of the compression chamber using three strokes of a straight edge, and the chamber was closed. After the first chamber was started, the second chamber was filled.

After testing was completed, the chamber was emptied, and the sample was weighed. A hand scoop and wet/dry vacuum were used to empty the compression chamber to ensure that the whole sample was retained. This allowed for evaluation of the initial bulk density within the chamber. The test weight was determined after each replication using a filling hopper, stand, and cup that met the USDA-GIPSA specifications (Seedburo, Chicago, Ill.).

Kernel density was measured for 25 of the 27 samples included in this study to evaluate if the asymptotic density $\left(\rho_{\infty}\right)$ used in equation 3 was approaching this value. A multi-pycnometer (MVP-1, Quantachrome Corp., Syosset,
N.Y.) was used to measure kernel density of each sample following the procedure provided in the owner's manual.

\section{Data Analysis}

Statistical analysis was performed to examine the influence of moisture content and sample on test weight using the GLM procedure in SAS (ver. 9.4, SAS Institute, Inc., Cary, N.C.). Moisture level and sample were treated as class variables, and the main effects of each were examined using Tukey's HSD test.

A nonlinear regression analysis was performed on the data for each pressure-density model using the "nlinfit" function in MATLAB (R2014B, The MathWorks, Natick, Mass.). The least squares regression was conducted with the robust option using the bisquare weight function, as this generally leads to a better fit. The $95 \%$ confidence intervals were determined for parameter estimates using the "nlparci" function. For each model, the predicted values were plotted against the observed values, and the correlation coefficients, root mean square error (RMSE), Akaike's information criterion (AIC), and corrected Akaike's information criterion (AICc) were computed. Motulsky (2004) recommended using the AIC value to compare non-nested models. This statistic is based on information theory and accounts for how well the model fits the data and the number of regression parameters. Additionally, by using AICc, the penalty for fitting additional parameters was increased. The model with the smallest AIC or AICc value has the highest probability of being correct. To further assess the regression performance, the root mean squared prediction error (RMSPE) was determined by applying the models developed to an independent data set used by Thompson et al. (1987).

\section{Data VALidation}

As previously discussed, the motivation behind developing these equations was to use them in conjunction with the differential form of Janssen's equation to estimate the total mass of grain in a storage structure. A subset of the developed models was validated using a portion of the data collected by Boac et al. (2015) for HRWW stored in steel and concrete bins. As described by Boac et al. (2015), the volume of grain in storage was determined from the bin geometry and the equivalent level height of grain. To account for variations in the grain surface topography, the equivalent level height of grain was estimated from multiple point measurements taken with a laser distance meter along the grain profile. The actual mass of grain in the bins was subsequently obtained from the producers for comparison. Thirty-five concrete bins ranging from 4.6 to $10.3 \mathrm{~m}$ in diameter with grain heights of 5.9 to $42.6 \mathrm{~m}$ in Oklahoma, Texas, and Kansas were used along with 16 corrugated steel bins in Kansas and Oklahoma ranging from 4.6 to $31.9 \mathrm{~m}$ in diameter and 4 to $25.6 \mathrm{~m}$ in fill height.

The general procedure to estimate the mass of grain in the bins was derived from Thompson et al. (1987), Ross et al. (1979), and McNeill et al. (2008). To estimate the mass of grain in the bin, the built-in ordinary differential equation solver (ODE45) in MATLAB was used in conjunction with the differential form of Janssen's equation, shown in 
equation 8 , and the various models to estimate the overburden pressure as a function of grain depth and the corresponding density increase:

$$
\frac{d P}{d y}=G D(P)-\frac{k P \mu}{R}
$$

where

$P=$ vertical overburden pressure within the bin $(\mathrm{kPa})$

$y=$ grain depth $(\mathrm{m})$

$g=$ gravitational acceleration constant $\left(\mathrm{kN} \mathrm{m}^{-3}\right)$

$D(P)=$ bulk density within the bin as a function of overburden pressure $\left(\mathrm{kg} \mathrm{m}^{-3}\right)$

$k=$ lateral to vertical pressure ratio (dimensionless)

$\mu=$ coefficient of friction of grain on bin wall (dimensionless)

$R=$ hydraulic radius $(\mathrm{m})$.

The initial bulk density of the grain in the top of the bin was assumed to be equal to the test weight with an overburden pressure of $0 \mathrm{kPa}$, and the models were used to estimate the bulk density as a function of overburden pressure and moisture content $(D(P))$. The values for $\mu(0.38$ for corrugated steel bins and 0.57 for concrete) and $k(0.5)$ were based on the authors' experience and were similar to Eurocode (2006). The bulk density of each layer was then estimated using the pressure-density models and the calculated pressures. From this, the mass of grain over each step size in the ODE solver was determined based on the bin's cross-sectional area and the total mass of grain determined using trapezoidal integration in MATLAB.

\section{RESULTS AND DISCUSSION}

\section{SAMPle Moisture Content ANd Test Weight}

The average test weights and moisture contents of the grain samples are shown in figure 1 . The error bars on each data point indicate one standard deviation $(n=4)$. There were variations in the equilibrium moisture content achieved at each temperature/RH set point, but an analysis of variance (ANOVA) showed that all three moisture levels were significantly different $(\alpha=0.05)$, and figure 1 shows a clear distinction between the three levels. The average

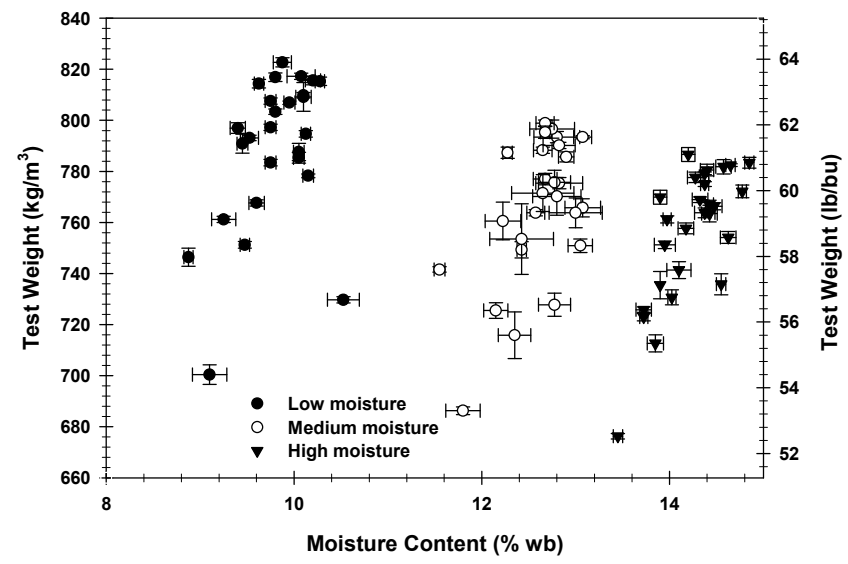

Figure 1. Moisture content and test weight distribution of 27 hard red winter wheat samples at three moisture levels. Error bars represent one standard deviation with $n=4$. moisture contents achieved were 9.8\% $\pm 0.4 \%, 12.6 \%$ $\pm 0.4 \%$, and $14.2 \% \pm 0.3 \%$ for the $10 \%, 12.5 \%$, and $14 \%$ nominal moisture levels, respectively.

An ANOVA also showed that the interaction between moisture level and sample had a significant $(p<0.001)$ effect on test weight; thus, the main effects of each were examined using Tukey's HSD test. The variation in test weight at each moisture level may have been due to the effects of variety, growing season, or location, as $89 \%$ of the sample comparisons were significantly different $(\alpha=$ $0.05)$. Tukey's test also showed that test weight differed significantly $(\alpha=0.05)$ among all three moisture levels.

\section{COMPARISON OF TEST WEIGHT TO INITIAL DENSITY IN COMPRESSION CHAMBER}

A comparison of the initial density produced during filling of the compression chamber to the test weight determined using the Winchester test cup is shown in figure 2. These values are linearly related, and the equation relating these two values is shown in figure 2. If the two measurements were identical, the slope of the line would be one and the intercept would be zero. In these tests, it was determined that the initial density of the grain within the compression chamber was slightly larger $(1.5 \%$ to $2 \%)$ than the test weight from the Winchester cup over this range of test weights. This difference was significant based on a t-test ( $\mathrm{p}<0.001)$. Kawakita and Lüdde (1971) noted that in models using the initial density as a parameter, deviations could sometimes be attributed to variation in the measured initial density caused by loading effects. Intuitively this makes sense because, in the absence of overburden pressure, the bulk density of the material as it is being loaded into the Winchester cup or the compression chamber is highly dependent on the particle arrangement and loading method. In the Winchester bushel test, grain flows slowly into the cup in a stream, while in the compression chamber the filling box instantaneously drops the grain into the chamber over the entire area of the chamber, and then the grain is leveled. These are two very different methods of filling. While some differences exist between the industry standard and compression chamber loading methods, the method used to load the compression chamber was found to produce more

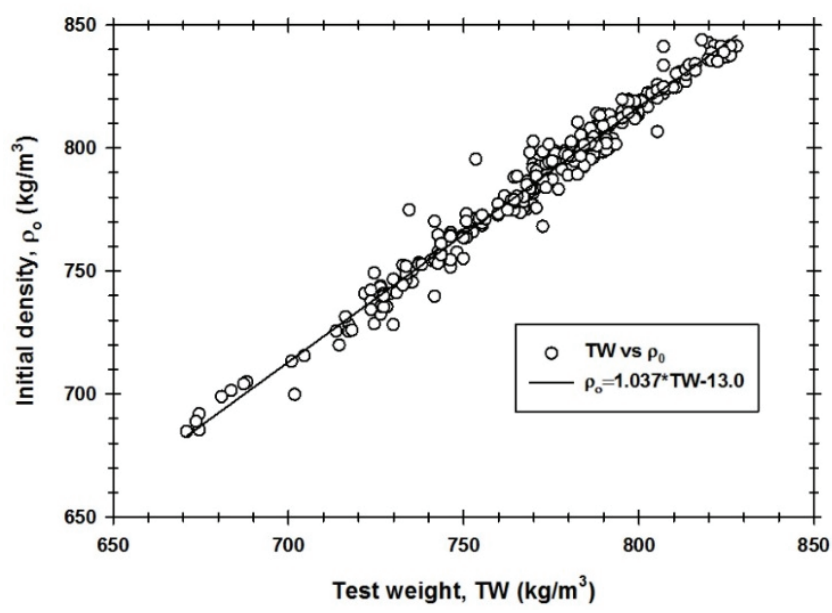

Figure 2. Relationship of test weight and initial density $\left(R^{2}=0.973\right)$. 
consistent results than other loading methods (Thompson, 1980). When fitting the models to the pressure-density relationship, the initial density in the sample container $\left(\rho_{o}\right)$ was used to account for this variation. This was found to produce a better fit to the laboratory data, and the resulting models performed better in the field validation. All of the models in this study used the initial density in the compression chamber instead of the test weight.

\section{CONFINED UniaXial CoMpression TEST RESUlts}

An example of the increase in bulk density as a function of overburden pressure for two different samples at two moisture contents is shown in figure 3. Sample 5 was variety Art from Oklahoma, while sample 14 was variety TAM 111 from Nebraska. Both varieties were from the 2009 crop year. Sample 5 had a test weight of $768 \mathrm{~kg} \mathrm{~m}^{-3}\left(59.6 \mathrm{lb} \mathrm{bu}^{-1}\right)$ and an initial density of $788 \mathrm{~kg} \mathrm{~m}^{-3}\left(61.2 \mathrm{lb} \mathrm{bu}^{-1}\right)$ in the compression chamber at the low moisture content $(9.6 \%$ w.b.). At the high moisture content ( $14.1 \%$ w.b.), sample 5 had a test weight of $741 \mathrm{~kg} \mathrm{~m}^{-3}\left(57.6 \mathrm{lb} \mathrm{bu}^{-1}\right)$ and an initial density of $757 \mathrm{~kg} \mathrm{~m}^{-3}\left(58.8 \mathrm{lb} \mathrm{bu}^{-1}\right)$ in the compression chamber. Sample 14 had a test weight of $751 \mathrm{~kg} \mathrm{~m}^{-3}\left(58.4 \mathrm{lb} \mathrm{bu}^{-1}\right)$ and an initial density of $770 \mathrm{~kg} \mathrm{~m}^{-3}\left(59.8 \mathrm{lb} \mathrm{bu}^{-1}\right)$ in the compression chamber at the low moisture content $(9.5 \%$ w.b.). Sample 14 had a test weight of $731 \mathrm{~kg} \mathrm{~m}^{-3}\left(56.8 \mathrm{lb} \mathrm{bu}^{-1}\right)$ and an initial density of $744 \mathrm{~kg} \mathrm{~m}^{-3}\left(57.8 \mathrm{lb} \mathrm{bu}^{-1}\right)$ in the compression chamber at the high moisture content (14.1\% w.b.). Each of the compressibility curves showed a similar trend at low pressures $(<40 \mathrm{kPa})$ where a rapid increase in bulk density occurred, which would be consistent with particle rearrangement. The density increase was based on the initial density in the compression chamber; therefore, all samples started at an observed density increase of $0 \mathrm{~kg} \mathrm{~m}^{-3}$. As the pressure continued to increase, the rate at which the bulk density increased was much less. At both moisture contents, sample 5 (with a significantly higher test weight and initial density in the compression chamber) had a slightly higher density increase. However, the density increase was not sig-

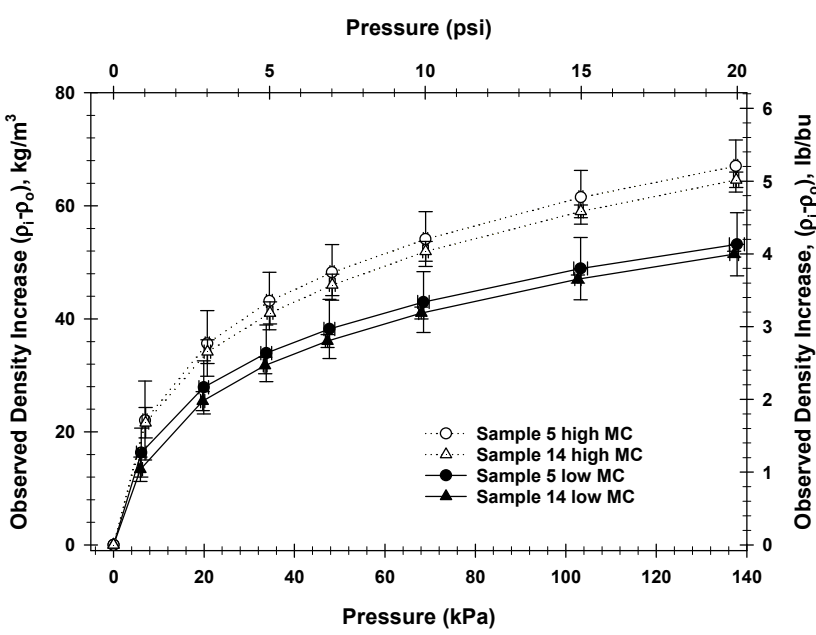

Figure 3. Results of typical confined uniaxial compression tests showing the increase in bulk density with pressure for samples 5 and 14 at two moisture levels. Sample 5 was variety Art from Oklahoma in 2009 and Sample 14 was variety TAM 111 from Nebraska in 2009. Error bars represent standard deviations with $n=4$. nificantly different from sample 14 over the pressure range examined.

\section{REGRESSION RESULTS}

Table 2 shows the estimated regression coefficients and their corresponding $95 \%$ confidence intervals for each of the models evaluated in this study. All of the models fit the data set reasonably well. Kernel density was measured for 25 of the 27 grain samples included in this study to evaluate the asymptotic density $\left(\rho_{\infty}\right)$ used in equation 3 . It was originally assumed that asymptotic density $\left(\rho_{\infty}\right)$ would approach the kernel or tapped density. The average kernel density measured was $1406 \mathrm{~kg} \mathrm{~m}^{-3}$ with a standard deviation of $28 \mathrm{~kg} \mathrm{~m}^{-3}$. The fitted value for $\rho_{\infty}$ using equation 3 was $976 \pm 8 \mathrm{~kg} \mathrm{~m}^{-3}$. These results indicate that the bulk density was not approaching an asymptote of the kernel density in the pressure range investigated in this study. This was further reinforced by the fact that the highest densities observed in this study were in the 850 to $900 \mathrm{~kg} \mathrm{~m}^{-3}$ range. Abhay et al. (2014) measured the tapped density of HRWW and found a tapped density of $821 \mathrm{~kg} \mathrm{~m}^{-3}$ at a moisture content of $12.1 \%$. The maximum density in the compression chamber and the tapped density were lower than the fitted value, and the kernel density was much higher, making the physical meaning of the asymptotic density unknown.

All of the models were evaluated for fit based on the $\mathrm{R}^{2}$, RMSE, and AICc criteria (table 3). The ranking of the models based on fit was the same regardless of the criteria. The RMSE and AICc indicated that none of the models included additional terms that overfit the data or penalized the model for fitting extra parameters. However, it is possible that the AICc score was offset by the amount of data in the analysis. The fitted exponent term in equation 2 did not substantially improve the fit over that of equation 1; thus, only the fixed polynomial equation was used in subsequent analysis.

Table 2. Model coefficients and $95 \%$ confidence intervals determined by nonlinear regression for the seven proposed equations.

\begin{tabular}{ccccccc}
\hline Eq. & $a$ & $b$ & $c$ & $d$ & $f$ & $\rho_{\infty}$ \\
\hline 1 & -0.488 & 6.569 & - & - & 2.03 & - \\
& \pm 0.028 & \pm 0.152 & & & \pm 0.163 & \\
\hline 2 & -0.417 & 7.181 & 0.455 & - & 2.0290 & - \\
& \pm 0.069 & \pm 0.693 & \pm 0.044 & & \pm 0.163 & \\
\hline 3 & 0.0466 & 0.3745 & - & - & 0.2417 & 975.6 \\
& \pm 0.0035 & \pm 0.0185 & & & \pm 0.1059 & \pm 7.6 \\
\hline 4 & 0.018 & 15.87 & 26.37 & 1.577 & 1.32 & - \\
& \pm 0.788 & \pm 11.74 & \pm 1.763 & \pm 0.436 & \pm 0.097 & \\
\hline 5 & 4.828 & 0.355 & 4.236 & - & - & - \\
& \pm 0.330 & \pm 0.011 & \pm 0.340 & & & \\
\hline 6 & 6.943 & 0.005 & - & - & 1.21 & - \\
& \pm 5.408 & \pm 0.001 & & & \pm 0.107 & \\
\hline 7 & -0.036 & 0.171 & - & - & -0.002 & - \\
& \pm 0.002 & \pm 0.034 & & & \pm 0.000 & \\
\hline
\end{tabular}

Table 3. Model descriptive statistics for the seven proposed equations.

\begin{tabular}{ccccc}
\hline Equation & $\mathrm{R}^{2}$ & $\begin{array}{c}\text { RMSE } \\
\left(\mathrm{kg} \mathrm{m}^{-3}\right)\end{array}$ & $\mathrm{AICc}$ & $\begin{array}{c}\text { RMSPE } \\
\left(\mathrm{kg} \mathrm{m}^{-3}\right)\end{array}$ \\
\hline 1 & 0.955 & 6.1 & 1914 & 8.5 \\
2 & 0.955 & 6.1 & 1914 & 8.4 \\
3 & 0.975 & 4.7 & 1722 & 10.2 \\
4 & 0.954 & 6.3 & 1923 & 9.3 \\
5 & 0.956 & 6.0 & 1909 & 8.1 \\
6 & 0.941 & 7.1 & 2000 & 11.7 \\
7 & 0.939 & 7.1 & 2015 & 13.4 \\
\hline
\end{tabular}


To measure the actual predictive capability of a regression model, the root mean squared prediction error (RMSPE) can be calculated using a validation data set (Neter et al., 1996). The RMSPE shown in table 3 was determined from the compressibility data for two varieties of HRWW tested by Thompson et al. (1987). RMSPE serves as an indication of how well the model will predict in the future. The data set from Thompson et al. (1987) was believed to be a good validation data set for the models considered in this study since it was an independent data set. The RMSPE increased slightly compared to the RMSE calculated with the samples from this study. A small change in the RMSPE compared to the RMSE indicates that the model would be appropriate for prediction in the future (Neter et al., 1996). Differences were expected between the validation data set from Thompson et al. (1987) because the varieties were developed over 20 years ago and were not part of the sample set tested in this research. Although the equipment and procedures used in this study were similar to those of Thompson et al. (1987), there were minor differences in the instrumentation, control system, and operator. McNeill et al. (2004) found slight differences between operators when identical equipment was used at two different locations. For this study, all samples were processed by one operator to reduce variation. Equations 1, 2, and 5 had the smallest RMSPE. However, the smallest increase in RMSPE was observed for equation 5, where the RMSE ranged from 6.02 to 8.13 for the prediction samples. Equations 6 and 7 had high values of RMSPE relative to the other models, which was consistent with what was seen for RMSE. The large increase from RMSE to RMSPE indicated that while equations 6 and 7 fit the data from this study reasonably well, they were not as well suited to predict the density increase for new samples (Neter et al., 1996). Equations 6 and 7 were excluded from further analysis because they had the highest values of RMSE, AICc, and RMSPE. Additionally, residual analysis of equation 7 showed a clear trend of overprediction.

RMSE and RMSPE have the same units as the dependent variable; thus, these metrics are relative to the scale of the dependent variable. When considering that the bulk densities in this study are in the 700 to $900 \mathrm{~kg} \mathrm{~m}^{-3}$ range, the values of RMSE and RMSPE are attractive (relatively small) for all of the models. This indicates that any of the models would be suitable to predict bulk density in a bin. Alternatively, these models were intended to model the density increase, which was generally less than $100 \mathrm{~kg} \mathrm{~m}^{-3}$. From this perspective, the values of RMSE and RMSPE were not as appealing, and the differences between the models were more important. However, the purpose of this analysis was to develop general equations that worked for a diverse range of samples.

To further evaluate the performance of these models, values of the measured versus predicted density increase $\left(\rho_{I}-\rho_{o}\right)$ of the four remaining models with the lowest RMSE, AICc, and RMSPE are plotted in figure 4. Equations 1, 4, and 5 showed a trend of predicting well at low density increases, overpredicting in the mid-range, and slightly overpredicting at the higher density increases.
Equation 3 generally fit closer to the 1: 1 line that indicates an exact fit, relative to the other models, and did not have a specific trend of over- or underprediction as the response variable increased. Except for equation 4, the rest of the equations returned a density increase of $0 \mathrm{~kg} \mathrm{~m}^{-3}$ at $0 \mathrm{kPa}$ overburden pressure because the differential density increase was based on the initial density of the sample within the test chamber.

To further examine these effects, three grain samples were selected and the density increase $\left(\rho_{i}-\rho_{o}\right)$ was plotted against overburden pressure. Neter et al. (1996) stated that graphically comparing nonlinear regression models for goodness of fit is a first step. These three samples were all from the 2009 crop year and were chosen because they had high, low, and average test weights. The predicted density increase using equations 1, 3, 4, and 5 was also plotted along with the experimental data. Figure 5 shows the density increase for a sample with a high test weight (variety Art from Nebraska in 2009). This variety had a test weight of $823 \mathrm{~kg} \mathrm{~m}^{-3}\left(63.9 \mathrm{lb} \mathrm{bu}^{-1}\right)$, average initial density of $841 \mathrm{~kg}$ $\mathrm{m}^{-3}$ in the compression chamber, and average moisture content of $9.9 \%$ (w.b.). Equation 3 followed the measured density increase closely compared to equations 1,4 , and 5 . Equations 1, 4, and 5 overpredicted the density increase for overburden pressures greater than $20 \mathrm{kPa}$.

The predicted and measured density increase for a variety with a low test weight (variety TAM 111 from Nebraska in 2009) is shown in figure 6 . This variety had a test weight of $751 \mathrm{~kg} \mathrm{~m}^{-3}\left(58.4 \mathrm{lb} \mathrm{bu}^{-1}\right)$, average initial density of $771 \mathrm{~kg} \mathrm{~m}^{-3}$ in the compression chamber, and average moisture content of $9.5 \%$ (w.b.). Equation 3 slightly overpredicted the measured density increase but tracked the measured data most closely. Above $40 \mathrm{kPa}$, equations 1, 4, and 5 underpredicted the measured data.

The predicted and measured density increase for a sample with an average test weight (variety Art from Oklahoma in 2009) is shown in figure 7. This sample had a test weight of $768 \mathrm{~kg} \mathrm{~m}^{-3}\left(59.6 \mathrm{lb} \mathrm{bu}^{-1}\right)$, average initial density of $788 \mathrm{~kg} \mathrm{~m}^{-3}$, and moisture content of 9.6\% (w.b.). Once again, equation 3 matched the experimental data closely, whereas equations 1, 4, and 5 underpredicted the experimental data.

\section{Application of Select Pressure-Density Models}

Based on the residuals, graphical observation of model performance, and RMSPE, equations 1, 3, 4, and 5 were selected for validation using field data from Boac et al. (2015). The initial density $\left(\rho_{o}\right)$ of the stored material on the grain surface was assumed equal to the test weight, and the predicted mass using Janssen's equation and the four candidate compressibility equations were compared to the actual mass of grain determined from scale records obtained by Boac et al. (2015). Table 4 shows the mean, median, and mean absolute errors, along with the tendency of the models to over- or underpredict the mass of grain in the bin. Results indicated that when each of the four top-ranking models was used in the differential form of Janssen's equation, the predicted mass of grain in the bins compared favorably with the measured mass. For concrete bins, the 


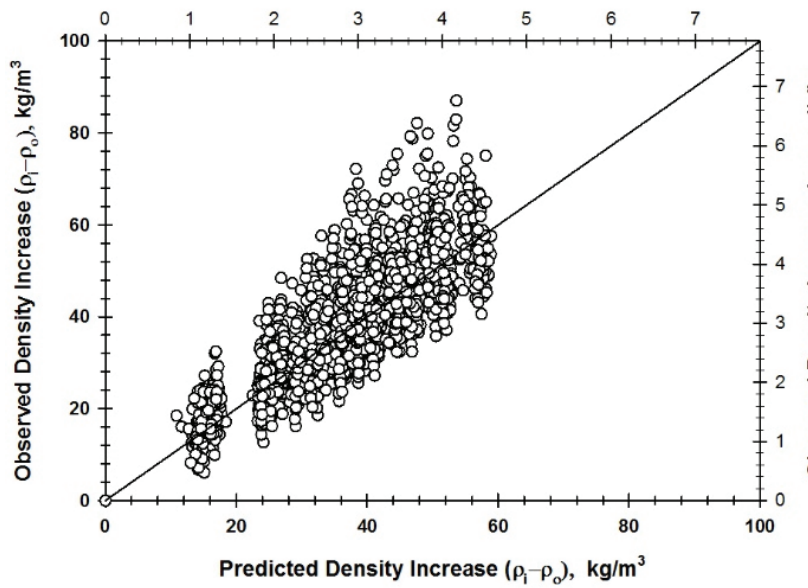

Equation 1

Predicted Density Increase $\left(\rho_{\mathrm{i}}-\rho_{\mathrm{o}}\right)$, Ib/bu

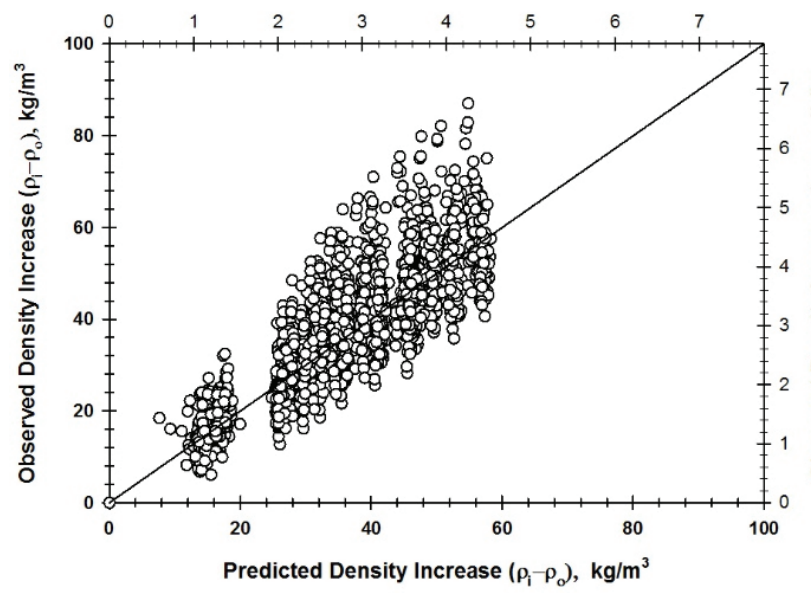

Equation 4

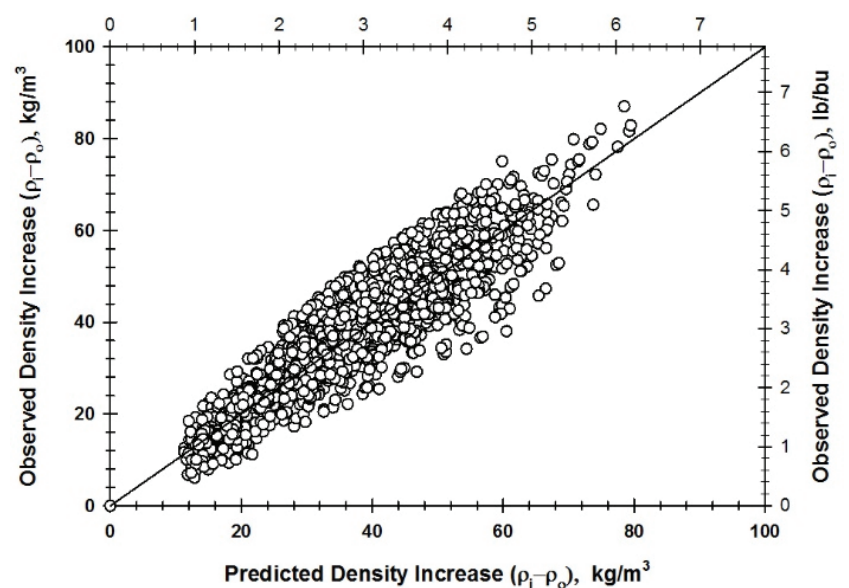

Equation 3

Predicted Density Increase $\left(\rho_{1}-\rho_{0}\right), \mathrm{lb} / \mathrm{bu}$

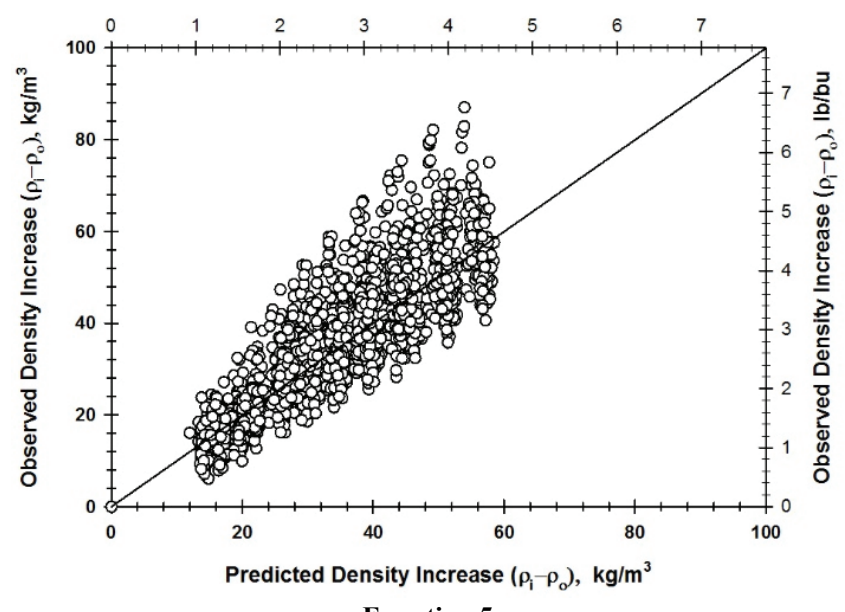

Equation 5

Figure 4. Predicted density increase plotted against observed density increase with a 1:1 line for four potential regression models.
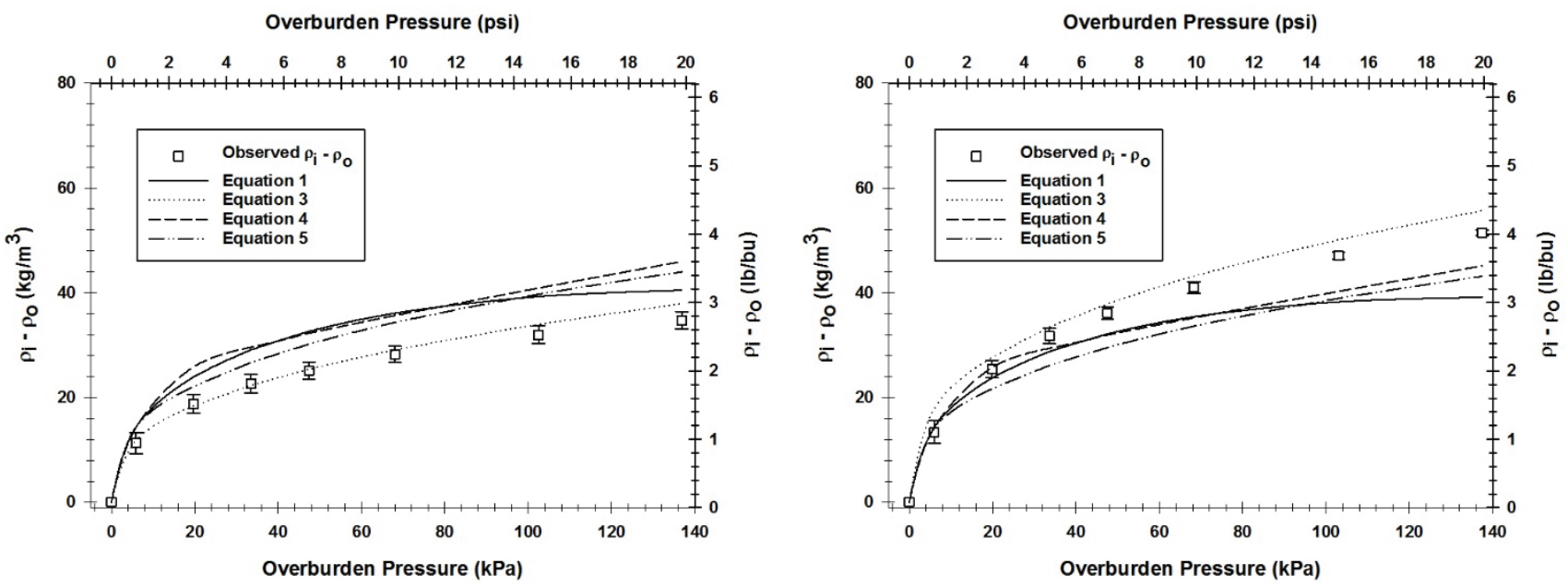

Figure 5. Predicted and measured density increase for a high test Figure 6. Predicted and measured density increase for a low test weight wheat sample (variety Art from Nebraska in 2009, test weight weight wheat sample (variety TAM 111 from Nebraska), test weight of of $826 \mathrm{~kg} \mathrm{~m}^{-3}$ at moisture content of $9.9 \%$ (w.b.) with initial density of $751 \mathrm{~kg} \mathrm{~m}^{-3}$ at moisture content of $9.5 \%$ (w.b.) with initial density of 771 $841 \mathrm{~kg} \mathrm{~m}^{-3}$ in the compression chamber.

$\mathrm{kg} \mathrm{m}^{-3}$ in the compression chamber.

median error was less than $2 \%$ for each of the models. This was an improvement for all but the RMA method examined by Boac et al. (2015), who found the median difference to be $3.5 \%, 1.03 \%$, and $2.16 \%$ for the FSA, RMA, and WPACKING methods, respectively. Similarly, for corrugated steel bins, the median error was less than $-2 \%$ for 


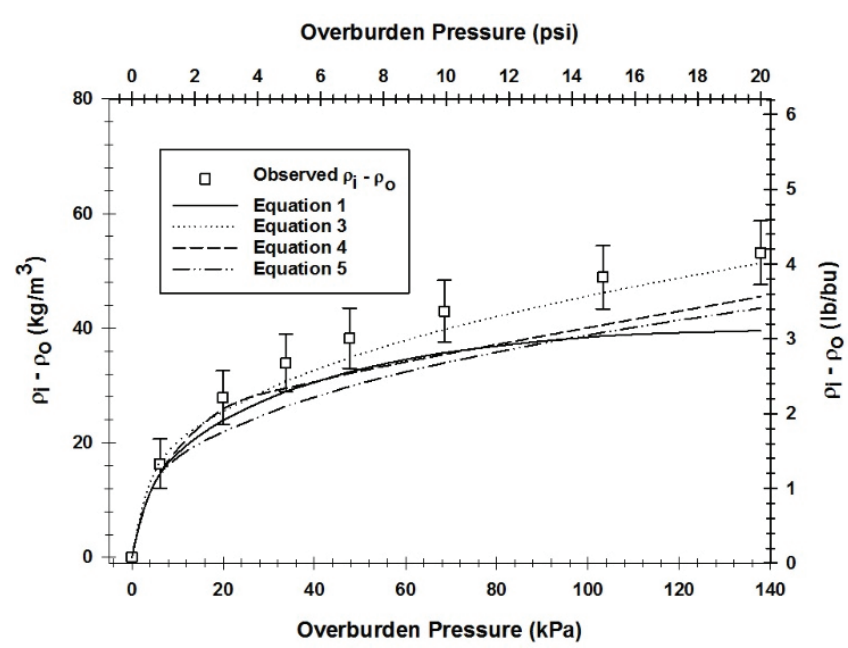

Figure 7. Predicted and measured density increase for an average test weight wheat sample (variety Art from Oklahoma in 2009), test weight of $768 \mathrm{~kg} \mathrm{~m}^{-3}$ at moisture content of $9.6 \%$ (w.b.) with initial density of $788 \mathrm{~kg} \mathrm{~m}^{-3}$ in the compression chamber.

Table 4. Errors associated with validating the four density models using field data from steel and concrete bins.

\begin{tabular}{lcccc}
\hline & \multicolumn{4}{c}{ Equation } \\
\cline { 2 - 5 } & 1 & 3 & 4 & 5 \\
\hline Concrete bins & & & & \\
Mean error (\%) & 1.53 & 1.83 & 1.53 & 1.34 \\
Mean absolute error (\%) & 3.54 & 3.45 & 3.53 & 3.47 \\
Median error (\%) & 1.64 & 1.71 & 1.66 & 1.30 \\
Bins underpredicted (\%) & 37.14 & 37.14 & 37.14 & 37.14 \\
Bins overpredicted (\%) & 62.86 & 62.86 & 62.86 & 62.86 \\
\hline Steel bins & & & & \\
Mean error (\%) & -1.74 & -1.22 & -1.80 & -1.87 \\
Mean absolute error (\%) & 1.92 & 2.09 & 1.97 & 2.00 \\
Median error (\%) & -1.52 & -1.09 & -1.60 & -1.65 \\
Bins underpredicted (\%) & 87.50 & 81.25 & 87.50 & 87.50 \\
Bins overpredicted (\%) & 12.50 & 18.75 & 12.50 & 12.50 \\
\hline
\end{tabular}

each of the proposed models, and equation 3 showed improvement over all three methods examined by Boac et al. (2015), who found the median difference to be $3.86 \%$, $1.91 \%$, and $-1.26 \%$ for the FSA, RMA, and WPACKING methods, respectively.

In concrete bins, the proposed models slightly overpredicted the grain mass compared to the scale data. Conversely, the proposed models led to an underprediction in steel bins. This could be due to a number of factors. The lateralto-vertical pressure ratio $(k)$ and the coefficient of friction of grain on the bin wall $(\mu)$ have a range of values reported in the literature but were assumed constant. The over/underprediction could be explained by errors associated with $\mu$ and $k$. Slight differences in these variables could increase or decrease the overburden pressure observed in a bin, which would in turn influence the bulk density and ultimately the predicted mass in the bin. Furthermore, errors in the approximation of the grain surface (uniform angle of repose, centered cone, etc.) used to estimate the volume of grain introduced additional variation.

The similar predictions observed with equations $1,3,4$, and 5 in field-scale bins could be explained by the similar RMSE calculated for each equation. When compared to the overall test weight of wheat $\left(772 \mathrm{~kg} \mathrm{~m}^{-3}\right)$, the RMSE of the prediction equations ranged from 4.7 to $6.3 \mathrm{~kg} \mathrm{~m}^{-3}$, which would result in an error between $0.6 \%$ and $0.8 \%$ relative to the test weight. This range appeared to match the data presented in table 4, where the range in the mean error was $0.49 \%$ in concrete bins and $0.65 \%$ in steel bins. The performance of the equations in table 4 did not correspond to the performance produced from table 3 . Equation 5 provided the best fit to the field data for concrete bins but was the worst performing equation in steel bins, and the RMSE was consistent with the other equations. In terms of RMSPE, equation 5 had the lowest RMSPE and provided the best prediction in concrete bins but was the worst in the steel bins. A number of factors could contribute to the contradictory behavior, such as the values chosen for $\mu$ and $k$ for the two bin types and the behavior of the compressibility equations up to a pressure of $50 \mathrm{kPa}$, where most of the packing occurred in these bin sizes.

\section{Conclusions}

Confined uniaxial compression tests were conducted on 27 samples of HRWW to examine the bulk compression behavior of the grain. Seven different models were fit to the data and were assessed using an independent data set and validated using field measurements in steel and concrete bins. Equations 1 through 5 all performed well based on RMSE and AICc, with no single model standing out in the statistical regression results (table 3). The RMSE ranged between 4.7 and $7.1 \mathrm{~kg} \mathrm{~m}^{-3}$, which represented an error of less than $1 \%$ when compared to the test weight of HRWW. Equation 3, which was the best performer based on $\mathrm{R}^{2}$, RMSE, and AICc, appeared to have randomly dispersed residuals and followed the 1:1 trend line between observed and predicted density increase better than the other models (fig. 4).

The models were validated using a data set from Thompson et al. (1987) based on RMSPE. Changes in RMSPE for the model validation showed similar trends for equations 1 through 5 , but in this case equation 5, not equation 3, was the top performer. The RMSPE was less than $10.2 \mathrm{~kg} \mathrm{~m}^{-3}$ for equations $1,3,4$, and 5 , which represented an error of less than $1.3 \%$ of the test weight.

Four of the best-fitting bulk density equations (eqs. 1, 3, 4 , and 5) were used in the differential form of Janssen's equation to predict the mass of grain in different-size corrugated steel and concrete bins. These values were compared to the actual mass of grain observed by Boac et al. (2015). The variation between models observed during the compressibility experiments did not translate to the field scale, and all of the models evaluated using field data had mean errors of less than $2 \%$. While equation 1 performed well with the field data and has been validated with the WPACKING program, it was not the best fitting model of the four models tested. Equation 3 was consistently one of the best fitting models with the field data.

\section{ACKNOWLEDGEMENTS}

This research was supported by the USDA (CRIS No. 5430-43440-007-00D). The information reported in this article (No. 15-05-072) is part of a project of the Kentucky 
Agricultural Experiment Station and is published with the approval of the Director.

\section{REFERENCES}

Abhay, P., Ambrose, R. P. K, Dogan, H., \& Casada, M. (2014). Wheat mill stream properties for discrete element method modeling. Trans. ASABE, 57(3), 891-899. $\mathrm{http} / / / \mathrm{dx}$. doi.org/10.13031/trans.57.10626

ASABE. (2011). ANSI/ASAE EP 433: Loads exerted by freeflowing grain on bins. St. Joseph, Mich.: ASABE.

ASABE. (2014). ANSI/ASAE S448.2: Thin-layer drying of agricultural crops. St. Joseph, Mich.: ASABE.

Bhadra, R., Turner, A. P., Casada, M. E., Montross, M. D., Thompson, S. A., Boac, J. M., ... Maghirang, R. G. (2015). Pack factor measurements for corn in grain storage bins. Trans. $A S A B E, 58(3), 879-890$. http://dx.doi.org/10.13031/trans.58.11033

Boac, J. M., Bhadra, R., Casada, M. E., Thompson, S. A., Turner, A. P., Montross, M. D., ... Maghirang, R. G. (2015). Stored grain pack factors for wheat: Comparison of three methods to field measurements. Trans. ASABE, 58(4), 1089-1101. http://dx.doi.org/10.13031/trans.58.10898

Clower, R. E., Ross, I. J., \& White, G. M. (1973). Properties of compressible granular materials as related to forces in bulk storage structures. Trans. ASAE, 16(3), 479-481. http://dx.doi.org/10.13031/2013.37547

Eurocode. (2006). EN 1991-4: Eurocode 1 - Actions on structures Part 4: Silos and tanks. Brussels, Belgium: European Union.

Gu, Z. H., Arnold, P. C., \& McLean, A. G. (1992). Consolidationrelated bulk density and permeability models for bulk solids. Powder Tech., 72(1), 39-44. http://dx.doi.org/10.1016/S00325910(92)85019-R

Hao, D., Zhang, Q., \& Britton, M. G. (1994). Effects of vibration on loads in a corrugated model grain bin. Canadian Agric. Eng., 36(1), 29-35.

Janssen, H. A. (1895). Verrsuche über getreidedruck in silozellen. Zeitschrift VDI, 39(35), 1045-1049.

Kawakita, K., \& Lüdde, K.-H. (1971). Some considerations on powder compression equations. Powder Tech., 4(2), 61-68. http://dx.doi.org/10.1016/0032-5910(71)80001-3

Kenkel, P., Noyes, R., Cuperus, G. W., Criswell, J., Fargo, S., \& Anderson, K. (1994). U.S. stored wheat pest management practices: Producers, elevator operators, and mills. In E. Highley, E. J. Wright, H. J. Banks, \& B. R. Champ (Eds.), Proc. 6th Intl. Working Conf. Stored-Product Protection, Vol. 2 (pp. 935-939). Wallingford, U.K.: CABI.

McNeill, S. G., Montross, M. D., Thompson, S. A., Ross, I. J., \& Bridges, T. C. (2008). Packing factors of feed products in storage structures. Appl. Eng. Agric., 24(5), 625-630. http://dx.doi.org/10.13031/2013.25260

McNeill, S. G., Thompson, S. A., \& Montross, M. D. (2004). Effect of moisture content and broken kernels on the bulk density and packing of corn. Appl. Eng. Agric., 20(4), 475-480. http://dx.doi.org/10.13031/2013.16477

Morgan, P. H., Mercer, L. P., \& Flodin, N. W. (1975). General model for nutritional responses of higher organisms. Proc. Natl. Acad. Sci., 72(11), 4327-4331.
Motulsky, H. (2004). Fitting models to biological data using linear and nonlinear regression: A practical guide to curve fitting. Oxford, U.K.: Oxford University Press.

Neter, J., Kutner, M. H., Nachtsheim, C. J., \& Wasserman, W. (1996). Applied linear statistical models (4th ed.). Chicago, Ill.: Irwin.

Overhults, D. G., White, G. H., Hamilton, H. E., \& Ross, I. J. (1973). Drying soybeans with heated air. Trans. ASAE, 16(1), 112-113. http://dx.doi.org/10.13031/2013.37459

Ross, I. J., Bridges, T. C., Loewer, O. J., \& Walker, J. N. (1979). Grain bin loads as affected by grain moisture content and vertical pressure. Trans. ASAE, 22(3), 592-597. http://dx.doi.org/10.13031/2013.35068

Steffe, J. F. (1992). Rheological methods in food process engineering. East Lansing, Mich.: Freeman.

Thompson, S. A. (1980). Physical properties of wheat and its relationship to vertical wall loads in grain bins. $\mathrm{PhD}$ diss. Lexington, Ky.: University of Kentucky.

Thompson, S. A., \& Ross, I. J. (1983). Compressibility and frictional coefficients of wheat. Trans. ASAE, 26(4), 1171-1176, 1180. http://dx.doi.org/10.13031/2013.34099

Thompson, S. A., McNeill, S. G., Ross, I. J., \& Bridges, T. C. (1987). Packing factors of whole grains in storage structures. Appl. Eng. Agric., 3(2), 215-221. http://dx.doi.org/10.13031/2013.26677

Thompson, S. A., Schwab, C. V., \& Ross, I. J. (1991). Calibration of a model for packing whole grains. Appl. Eng. Agric., 7(4), 451-456.

USDA. (1999). Grain grading procedures. Washington, D.C.: USDA Grain Inspection, Packers, and Stockyards Administration.

USDA. (2011). Loss adjustment manual (LAM) standards handbook. Washington, D.C.: USDA. Retrieved from www.rma.usda.gov/handbooks/25000/2011/11_25010.pdf

USDA. (n.d.). Warehouse examiner's handbook grain pack data. Washington, D.C.: USDA.

\section{NoMENCLATURE}

$a, b, c, d, f=$ parameters determined by least squares fit $D(P)=$ bulk density as a function of pressure and moisture content $\left(\mathrm{kg} \mathrm{m}^{-3}\right)$

$G=$ gravity constant $\left(9.81 \times 10^{-3} \mathrm{kN} \mathrm{kg}^{-1}\right)$

$k=$ lateral-to-vertical pressure ratio (dimensionless)

$M=$ moisture content (decimal dry basis)

$P=$ overburden pressure $(\mathrm{kPa})$

$R=$ hydraulic radius of storage structure $(\mathrm{m})$

$T W=$ sample test weight $\left(\mathrm{kg} \mathrm{m}^{-3}\right)$

$y=$ depth of material in the bin (m)

$\mu=$ coefficient of friction of material on bin wall (dimensionless)

$\rho_{i}=$ sample bulk density at a given pressure $\left(\mathrm{kg} \mathrm{m}^{-3}\right)$

$\rho_{o}=$ initial sample bulk density $\left(\mathrm{kg} \mathrm{m}^{-3}\right)$

$\rho_{\infty}=$ asymptotic value of density (additional parameter determined by least squares best fit, $\mathrm{kg} \mathrm{m}^{-3}$ ) 